\section{An Approach to}

High-Performance

Affordable Housing

Using Point-Source

Space Conditioning

Is it possible to reduce space-conditioning energy consumption by $50 \%$, while maintaining home affordability and thermal comfort?

In cooperation with the Building America Program, The Levy Partnership explored a variety of options to reduce space-conditioning energy consumption, working with partners to design, manufacture, and build test homes in three states.

The Levy Partnership tested the use of minisplit ductless heat pumps in combination with small through-wall transfer fans to provide space conditioning in small single-story homes, including manufactured homes and homes built by Habitat for Humanity.

The team set out to achieve $50 \%$ less energy consumption, compared to the 2009 International Energy Conservation Code, while maintaining home

\section{Project Information \\ Building Component: \\ Space-conditioning \\ Team and Partners: The Levy \\ Partnership, Affordable Housing Alliance, Champion Homes, Habitat for Humanity, Southern Homes}

Application: Residential

Years Tested: 2016-2019
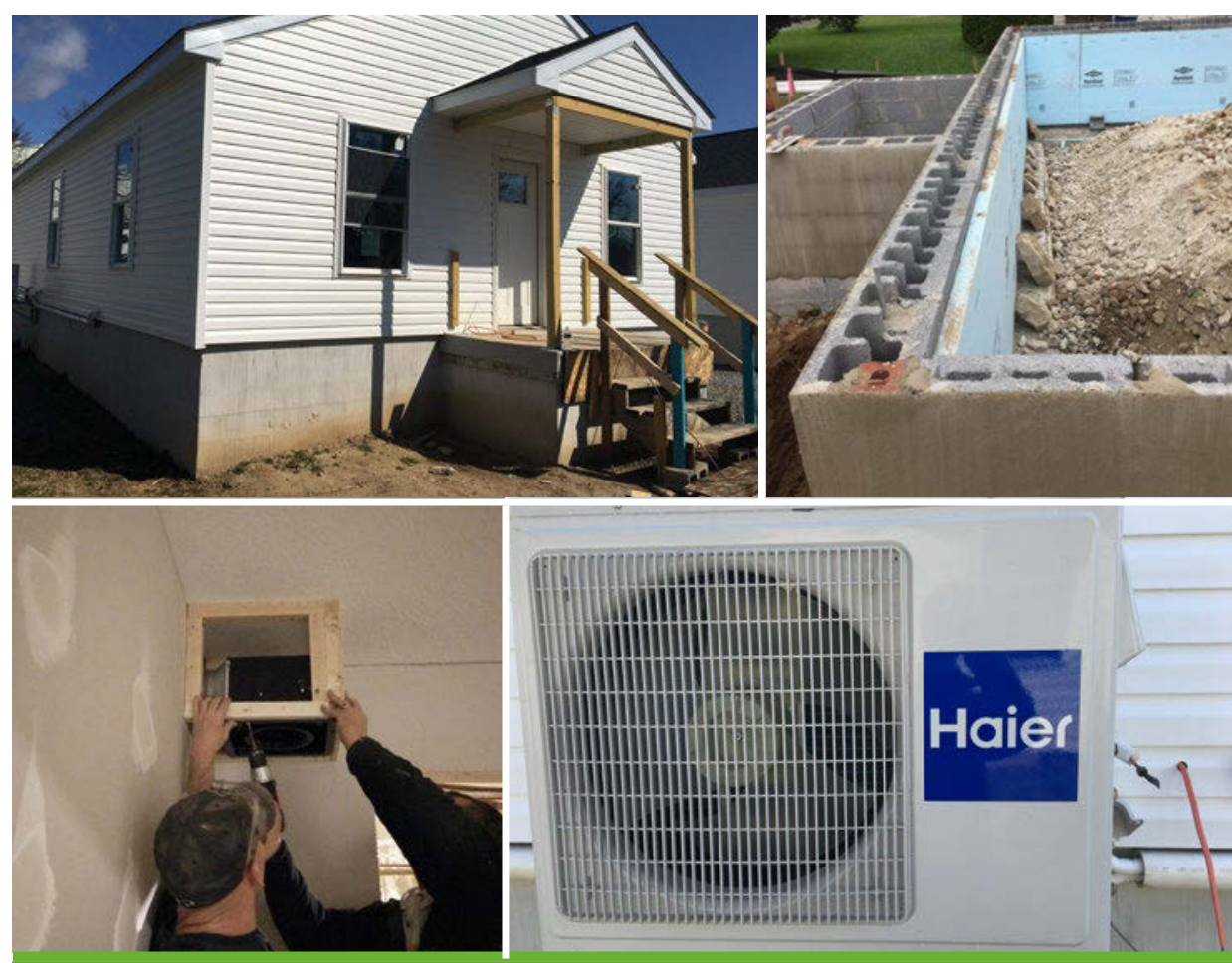

Single-story home showcasing the use of minisplit ductless heat pumps in combination with small through-wall transfer fans and highly efficient thermal envelope to provide space conditioning. Photos from The Levy Partnership affordability and thermal comfort. The strategy also included a highly efficient thermal envelope to reduce space-conditioning loads.

\section{Technical Approach}

Research began with the development of a simulation model using Transient Systems Simulation (TRNSYS) and Multi-zone Airflow and Contaminant
Transport Analysis (CONTAM) software calibrated to previously collected data from a lab home in Alabama. The model allowed the team to compare alternative designs and predict performance as a function of variations in building configurations and climates. The simulation tools provided information used to test new distribution system designs in the field, first by retrofitting the Alabama lab home.

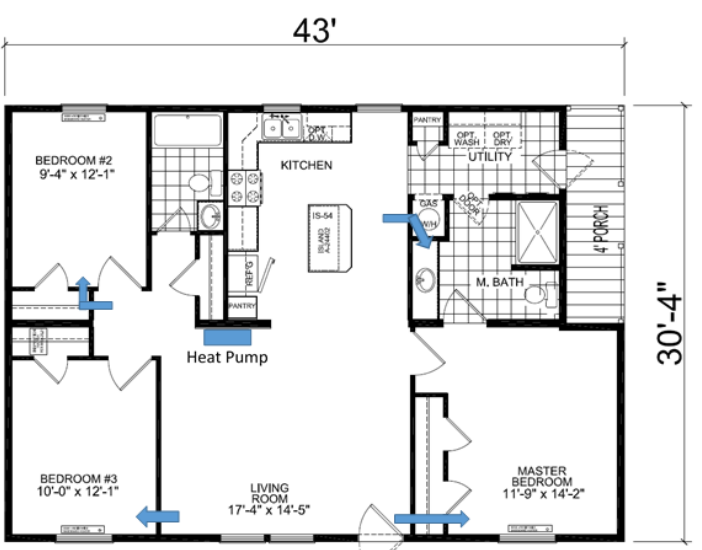

New Jersey home floor plan, showing heat pump (blue rectangle) and transfer fans (blue arrows). A series of alternative specifications were modeled with the TRNSYS software. Figure from Center The Levy Partnership 


\begin{tabular}{|c|c|}
\hline Site Name & Notable Findings by Site \\
\hline $\begin{array}{l}\text { New Jersey } \\
\text { home }\end{array}$ & $\begin{array}{l}\text { - Space-conditioning source energy savings was modeled at greater than } 50 \%, \text { compared to the } 2009 \text { International Energy } \\
\text { Conservation Code. } \\
\text { - Comfort compliance in heating mode was achieved with the limited use of supplemental electric resistance heating. } \\
\text { - Cooling season temperature data showed potential for compliance with some set point adjustment, but did not meet relative } \\
\text { humidity criteria, although humidity was not reported as problematic by occupants and no moisture concerns were observed. } \\
\text { - Residents were satisfied with the home comfort and energy bills. }\end{array}$ \\
\hline $\begin{array}{c}\text { Massachusetts } \\
\text { home }\end{array}$ & $\begin{array}{l}\text { - Space-conditioning source energy savings were } 27 \%-45 \% \text { compared to a gas-heated home and } 66 \%-74 \% \text { compared to electric } \\
\text { resistance, depending on whether it is compared to a best case or a supplemental heating case model. } \\
\text { - Home had more challenging layout, small but significant thermal defects in the envelope, missing fan controls, and occupant prefer- } \\
\text { ences that were at odds with some basic strategies of the space-conditioning system. }\end{array}$ \\
\hline $\begin{array}{l}\text { Maryland } \\
\text { home }\end{array}$ & $\begin{array}{l}\text { - Challenging layout, similar to the Massachusetts home } \\
\text { - Similar energy savings as the New Jersey home, exceeding project goals when gas and electric baselines are averaged. } \\
\text { - Two indoor heat pump air handlers were installed, instead of one in Massachusetts (living room and a bedroom) } \\
\text { - Residents were satisfied with comfort, although their use of the heat pumps and fans (and lack of use) impacted the comparison to } \\
\text { the comfort metrics. }\end{array}$ \\
\hline
\end{tabular}

The team tested the approach by building a manufactured home in New Jersey. The test home allowed data collection under simulated occupancy conditions for one year, and then the home was monitored for an additional year when occupied. Two additional test homes were then built with Habitat for Humanity affiliates (in Massachusetts and Maryland) and monitored for one year of occupancy.

Monitoring at all three test homes included space-conditioning energy consumption and thermal comfort metrics.

\section{Findings}

The potential benefits of this approach compared to traditional code-minimum homes with central forced air spaceconditioning include less noise from large air handlers and high volumes of moving air; low energy bills and the ability to make the short jump to net zero energy with the addition of photovoltaics; passive resiliency due to the superior thermal envelope; and homeownership costs similar or lower than standard homes when factoring in the first costs and monthly energy bills. Because the space-conditioning system is atypical, it may take some getting used to and may not be a good fit for all occupants.
Key lessons gleaned from the test homes include:

- Supplemental heaters can be controlled to minimize their use by offsetting set points from the heat pump set point.

- Transfer fans and ventilators should be occupant controllable with clearly labeled on-off switches.

- Short circuiting of the transfer fan airflow should be avoided; transfer fan capacity should be in the 90-150 $\mathrm{cfm}$ range to move the needed amount of energy into or out of a room, and adjustable fans can permit tweaking the flow rate by season or based on occupant preference to improve comfort.

- This approach works better for compact home layouts that organize remote spaces around and directly adjacent to the main living space, rather than elongated or L-shaped plans or floor plans with the main living space at one end of the home.

- A common challenge with any lowload home, humidity levels remained difficult to control as the heat pumps did not dehumidify the low-load homes to meet comfort criteria.

\section{Learn More}

Guideline documents were prepared for the manufactured home industry and for Habitat (and builders of similar homes) to help them apply the lessons from this work if they wish to adopt this approach for highperformance buildings.

\section{Technical Report:}

https://www1.eere.energy.gov/ buildings/pdfs/78166.pdf

\section{U.S. DEPARTMENT OF}

\section{ENARQY}

Office of

ENERGY EFFICIENCY \&

RENEWABLE ENERGY

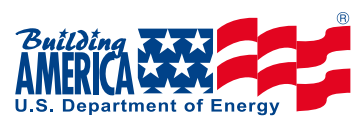

\section{THE LEVY PARTNERSHIP}

For more information, visit: energy.gov/ eere/buildings/building-america

DOE/GO-102021-5569 • June 2021

Produced for the U.S. Department of Energy, Office of Energy Efficiency and Renewable Energy, by the National Renewable Energy Laboratory (NREL). 